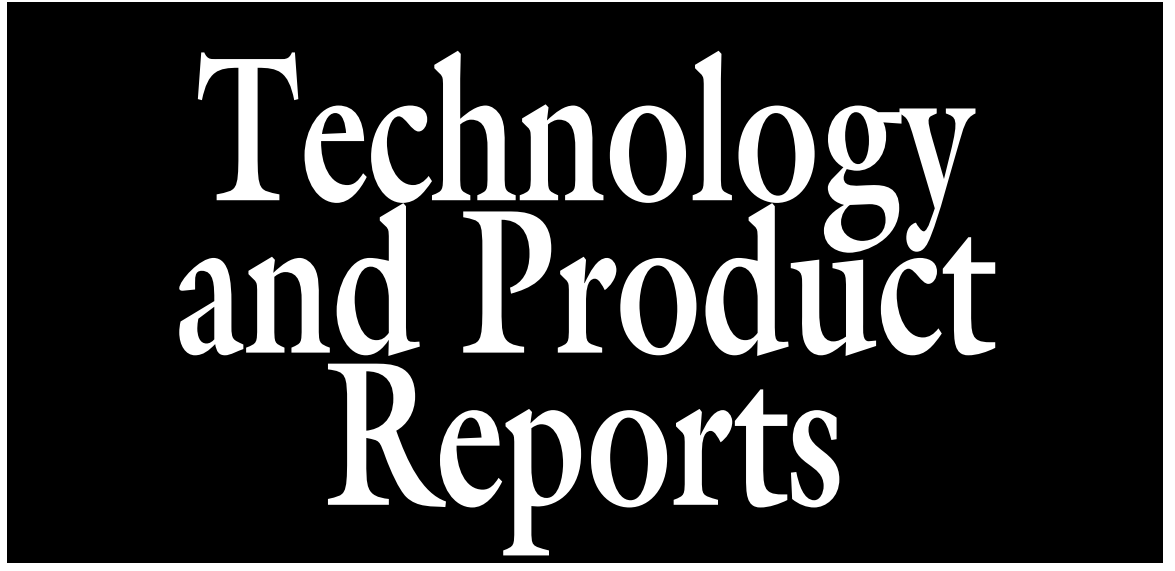

\section{Release Rates of Soluble and Controlled-release Boron Fertilizers}

\author{
Timothy K. Broschat ${ }^{1}$
}

AdDitional INDEX words. boric oxide, frits, colemanite, ulexite, probertite, sodium borates

SUMMARY. The relative release rates of boron (B) from nine soluble and controlled-release B fertilizer sources were determined in sand leaching columns at $21{ }^{\circ} \mathrm{C}$. Solubor was almost completely leached from the sand within 5 weeks. Boric oxide released the majority of its B within 7 weeks, whereas Dehybor provided $B$ for up to 13 weeks. Granubor release rates were linear through $\approx 12$ weeks. The five products containing calcium or sodium calcium borates released $\mathrm{B}$ much more slowly, with probertite and ulexite being the most rapid followed by B32 G, colemanite, and B38 G. B38 G released only $\approx 40 \%$ of its $B$ content during the 104-week leaching study. The rapid release and high $B$ concentrations associated with Solubor suggest a greater potential for phytotoxicity with this source than other slower-release sources.

$\mathrm{B}$ oron (B) deficiency is an important problem in the production of many crops around the world (Reisenauer et al., 1973; Sharrocks, 1997). Although B deficiency is known to be accentuated by soil drying and high soil $\mathrm{pH}$ (Biggar and Fireman, 1960; Keren and Gast, 1981), it is also common in wet climates (Moraghan and Mascagni, 1991). Because B is available to plants only in water-soluble forms such as boric acid or borate anions, it is highly leachable, particularly on coarse-textured soils (Sharrocks, 1997). Boron is slowly released from organic matter or soil minerals (Peryea et al., 1985),

University of Florida, Environmental Horticulture Department, Ft. Lauderdale Research and Education Center, 3205 College Avenue, Ft. Lauderdale, FL 33314

This research was supported by the Florida Agricultural Experiment Station.

I thank Anita Durden, William Latham, and Susan Thor for their assistance in this project.

${ }^{1}$ Corresponding author. E-mail: tkbr@ufl.edu. but under conditions of high rainfall or irrigation, temporary deficiencies of $B$ in the soil can occur and may result in visible deficiency symptoms in the new growth of plants (Sharrocks, 1997).

For many fruit and vegetable crops, well-timed foliar applications of water-soluble B fertilizers are a common practice to prevent deficiencies (Martens and Westermann, 1991). For perennial crops, prevention of $\mathrm{B}$ deficiencies may be achieved through the use of controlled-release $B$ fertilizers that are not greatly affected by leaching (Page and Cooper, 1955). In slow-growing plants such as palms (Palmae family), chronic and recurring acute $\mathrm{B}$ deficiencies are a widespread and serious problem (Broschat, 2007; Corrado et al., 1992; Manciot et al., 1980). In these situations, the use of controlledrelease $B$ fertilizers should be more effective than treatment of these deficiencies after the fact. Although controlled-release B fertilizers have been available for many years, little is known about the relative release rates of the various products under similar leaching conditions. Knowledge about the relative longevities of controlledrelease $B$ fertilizers under leaching conditions would be useful for determining reapplication intervals and thereby avoiding potential toxicity situations or lapses in B availability. The purpose of this study was to determine the relative release rates of nine soluble and controlled-release B fertilizers.

\section{Materials and methods}

Polyvinyl chloride columns (12 inches long $\times 2$ inches i.d.) were mounted vertically into Buchner funnels $(70 \mathrm{~mm}$ in diameter $)$ that were supported by special funnel support racks. Columns were filled to a depth of $28 \mathrm{~cm}$ with medium-grade (14\% less than $0.5 \mathrm{~mm}, 18 \%$ greater than $1.0 \mathrm{~mm}$ ) acid-washed silica sand. This sand was prepared by rinsing thoroughly with tap water, soaking for $48 \mathrm{~h}$ in $1 \mathrm{~N}$ ammonium hydroxide, rinsing thoroughly with tap water, soaking for $48 \mathrm{~h}$ in $1 \mathrm{~N}$ hydrochloric acid, and finally leaching with a minimum of $12 \mathrm{~L}$ of deionized water per 4-L batch of sand (Hewitt, 1952).

Five grams of each of the nine Bcontaining fertilizers (Table 1 ) were applied to the sand surface of three replicate columns per product. The columns were maintained at $21 \pm 1^{\circ} \mathrm{C}$. They were irrigated three times per week with $50 \mathrm{~mL}$ of deionized

\begin{tabular}{llll}
\hline $\begin{array}{l}\text { Units } \\
\text { To convert U.S. to SI, } \\
\text { multiply by }\end{array}$ & U.S unit & SI unit & $\begin{array}{l}\text { To convert SI to U.S., } \\
\text { multiply by }\end{array}$ \\
\hline 10 & $\%$ & $\mathrm{mg} \cdot \mathrm{g}^{-1}$ & 0.1 \\
29.5735 & $\mathrm{fl} \mathrm{oz}$ & $\mathrm{mL}$ & 0.0338 \\
3.7854 & gal & $\mathrm{L}$ & 0.2642 \\
2.54 & inch $(\mathrm{es})$ & $\mathrm{cm}$ & 0.3937 \\
25.4 & inch $(\mathrm{es})$ & $\mathrm{mm}$ & 0.0394 \\
1 & $\mathrm{ppm}$ & $\mathrm{mg} \cdot \mathrm{L}^{-1}$ & 1 \\
$\left({ }^{\circ} \mathrm{F}-32\right) \div 1.8$ & ${ }^{\circ} \mathrm{F}$ & ${ }^{\circ} \mathrm{C}$ & $\left(1.8 \times{ }^{\circ} \mathrm{C}\right)+32$
\end{tabular}


Table 1. Boron (B) fertilizer materials evaluated for their release rates in sand columns.

\begin{tabular}{|c|c|c|c|c|}
\hline Product & Composition & B (\%) & $\begin{array}{c}\text { Particle } \\
\text { size }(\mathrm{mm})^{\mathrm{z}}\end{array}$ & Source \\
\hline B32 G & Sodium calcium borates & 10.0 & $4+1$ & Frit Industries, Walnut Ridge, AR \\
\hline Colemanite & Calcium borate & 16.6 & -0.074 & $\begin{array}{l}\text { American Borate Co., } \\
\text { Amargos Valley, NV }\end{array}$ \\
\hline Probertite-7 mesh & Sodium calcium borate & 5.9 & $-2.83+0.42$ & American Borate Co. \\
\hline Dehybor-12 mesh & Anhydrous sodium tetraborate & 22.5 & -1.68 & U.S. Borax \\
\hline Boric oxide- 4 mesh & Anhydrous boric acid & 32.3 & -4.76 & U.S. Borax \\
\hline Solubor & Disodium octaborate tetrahydrate & 20.5 & -0.074 & U.S. Borax \\
\hline
\end{tabular}

${ }^{\mathrm{z} A}$ minus (-) sign indicates that $90 \%$ of the particles will pass through this size sieve opening. A plus (+) sign indicates that $90 \%$ will be retained by this sized sieve opening $(1 \mathrm{~mm}=0.0394 \mathrm{inch})$

water, and all leachates were collected in polyethylene beakers. Once per week the leachate volumes were measured (leaching fraction averaged 0.73 ) and the samples were analyzed for $\mathrm{B}$ concentrations using inductively coupled plasma emission spectroscopy (Keren, 1996). Three replicate columns containing no fertilizer were also included as controls, although no measurable amounts of $B$ were ever recovered from these columns. The amount of B in each sample was divided by the percentage of $\mathrm{B}$ in each fertilizer to correct for differences in percentages of $\mathrm{B}$ among products. Weekly sampling continued for a particular product until leachate $\mathrm{B}$ concentrations dropped below $1 \mathrm{mg} \cdot \mathrm{L}^{-1}$ or 104 weeks, whichever came first. Results were expressed as milligrams of $B$ released per week per gram of $B$ applied and as the cumulative percentage of applied B released over time. Cumulative release curve equations were developed using TableCurve 2D (v2.03; Systat Software, San Jose, CA).

\section{Results}

Weekly release of B varied greatly among the nine products tested (Fig. 1A-B). As expected, Solubor released most rapidly with virtually no $\mathrm{B}$ detected in the leachate after 5 weeks (Fig. 1A). The highest B concentrations from Solubor were obtained during weeks 1 to 3 when more than $70 \%$ of its $\mathrm{B}$ was released (Fig. 2A). However, only $\approx 83 \%$ of the total B content of Solubor was ever recovered in the leachate. The reasons for this low recovery rate are not known.
Boric oxide had the second fastest release rate with the majority of its $\mathrm{B}$ released in the first 7 weeks (Figs. $1 \mathrm{~A}$ and $2 \mathrm{~A}$ ). Approximately $90 \%$ of the $\mathrm{B}$ in this product was ultimately recovered in the leachates (Fig. 2A).

The majority of Dehybor's B was released within the first 9 weeks with
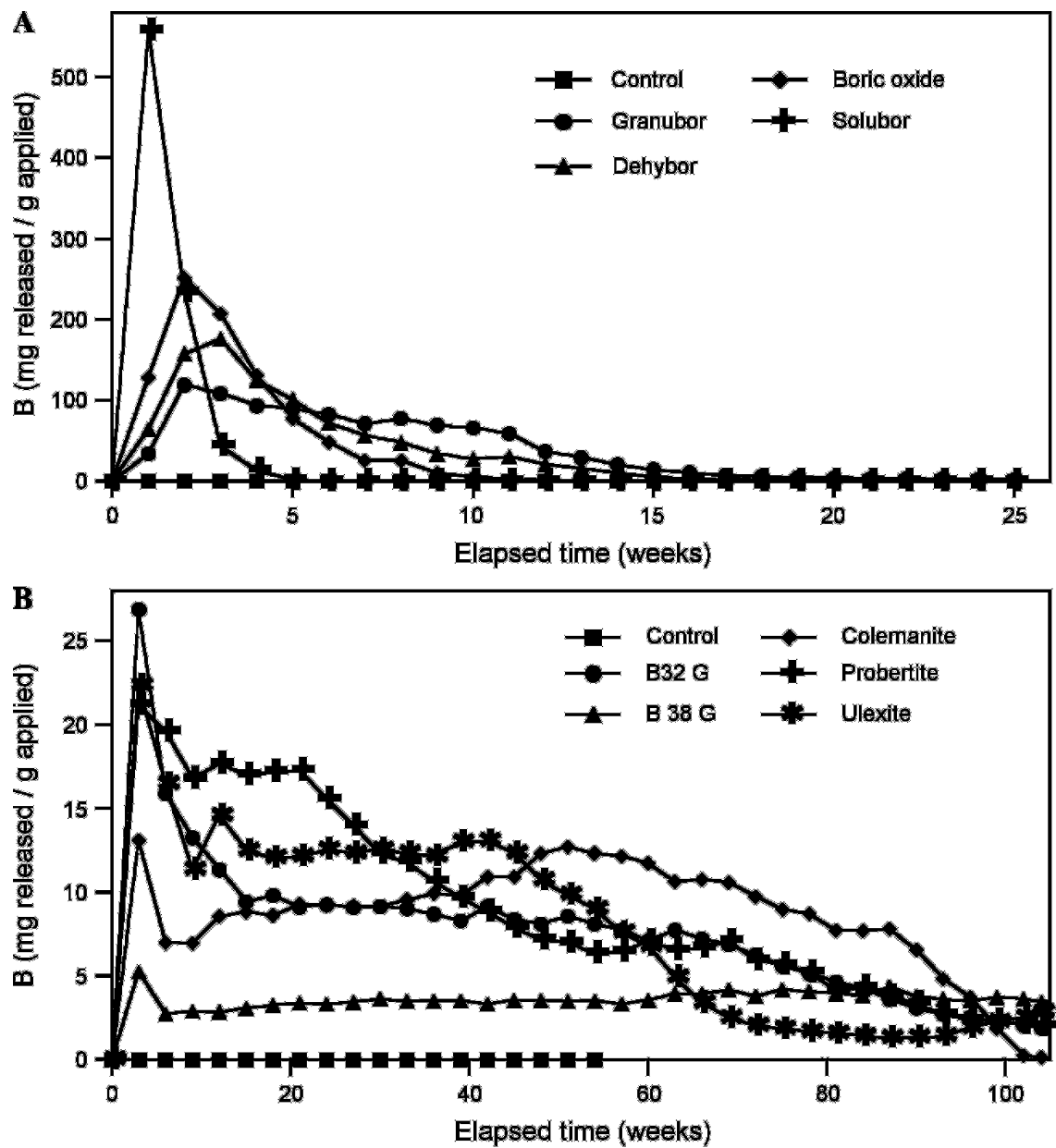

Fig. 1. Weekly release of boron (B) from soluble and controlled-release $B$ fertilizers. (A) Release of B from soluble and short-term controlled-release products. (B) Release of B from longlasting products. Data are means from three replicate columns \pm SE. Granubor, Solubor, and Dehybor are manufactured by U.S. Borax, Inc., Valencia, CA. B 32 G and B 38 G are manufactured by Frit Industries, Walnut Ridge, AR (1 mg. $\left.\mathrm{g}^{-1}=0.1 \%\right)$. 

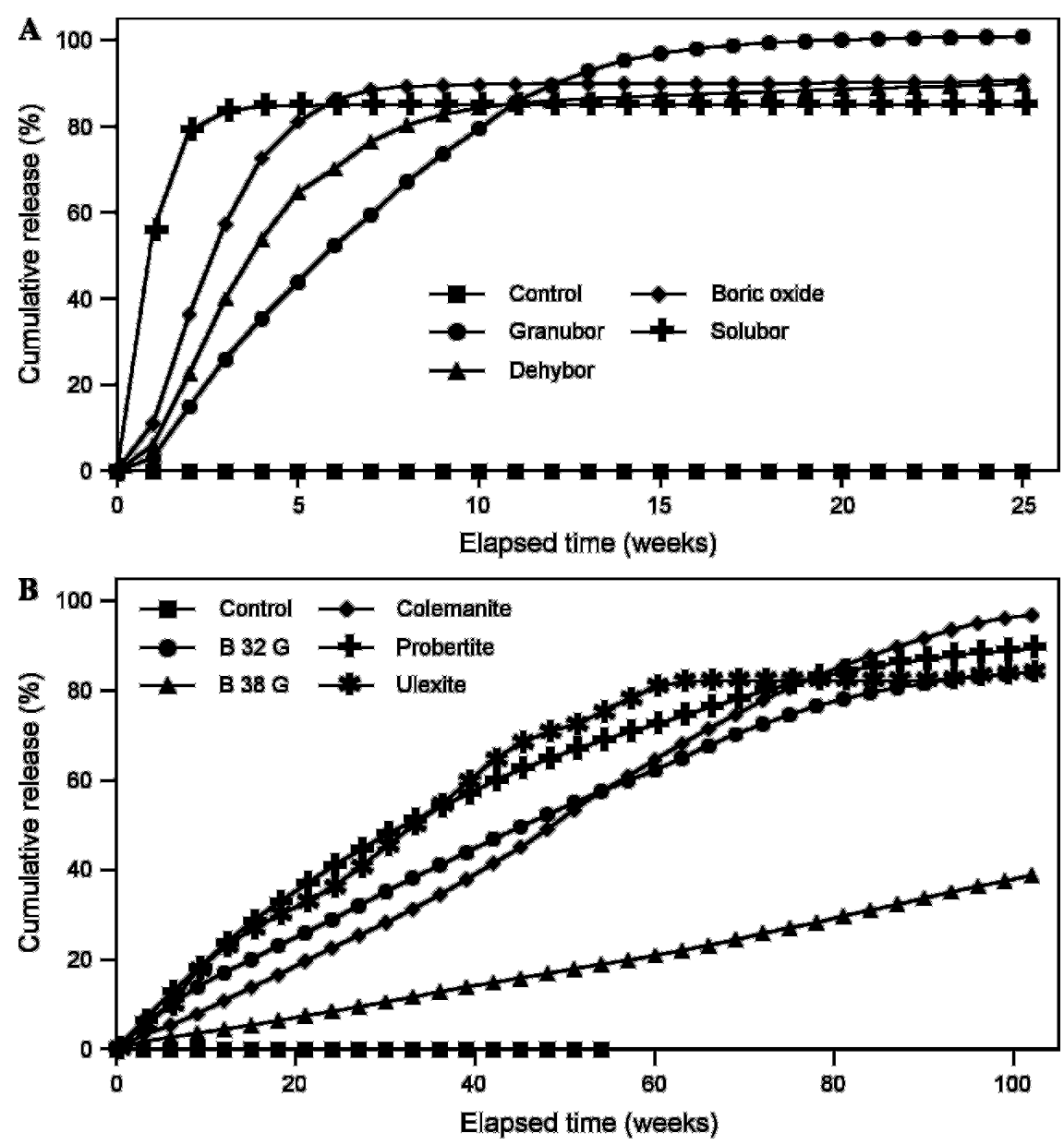

Fig. 2. Cumulative percent release of boron (B) from soluble and controlled release B fertilizers. (A) Release of B from soluble and short-term controlled-release products. (B) Release of B from longlasting products. Data are means from three replicate columns \pm SE. Regression equations for these curves are shown in Table 2 . Granubor, Solubor, and Dehybor are manufactured by U.S. Borax, Valencia, CA. B32 G and B38 G are manufactured by Frit Industries, Walnut Ridge, AR.

Table 2. Equations for cumulative percent release curves for nine soluble and controlled-release boron fertilizers

\begin{tabular}{llcc}
\hline Product & \multicolumn{1}{c}{ Equation } & $\mathbf{R}^{2}$ & $P$ \\
\hline${\mathrm{B} 32 \mathrm{G}^{\mathrm{y}}}^{\mathrm{B} 38 \mathrm{G}^{\mathrm{y}}}$ & $\mathrm{y}=0.98+1.90 \mathrm{x} \ln \mathrm{x}$ & 0.994 & 0.0001 \\
Colemanite & $\mathrm{y}=2.14+0.078 \mathrm{x} \ln \mathrm{x}$ & 0.998 & 0.0001 \\
Probertite & $\mathrm{y}=-0.747+1.036 \mathrm{x}$ & 0.992 & 0.0001 \\
Ulexite & $\mathrm{y}=-8.133+10.16 \mathrm{x}^{0.5}$ & 0.989 & 0.0001 \\
Granubor $^{\mathrm{z}}$ & $\mathrm{y}=-0.518+2.55 \mathrm{x}^{0.5} \ln \mathrm{x}$ & 0.994 & 0.0001 \\
Dehybor $^{\mathrm{z}}$ & $\mathrm{y}=-15.74+28.44 \mathrm{x}^{0.5}$ & 0.961 & 0.0001 \\
Boric oxide $_{\text {Solubor }}^{\mathrm{z}}$ & $\mathrm{y}=-10.69+30.82 \mathrm{x}^{0.5}$ & 0.944 & 0.0001 \\
S $^{-1}$ & $\mathrm{y}=0.011+0.126 \mathrm{e}^{-\mathrm{x}}$ & 0.989 & 0.0001 \\
& $\mathrm{y}=88.2-87.94 \mathrm{e}^{-\mathrm{x}}$ & 0.998 & 0.0001 \\
\hline
\end{tabular}

${ }^{2}$ Manufactured by U.S. Borax, Valencia, CA.

${ }^{y}$ Manufactured by Frit Industries, Walnut Ridge, AR.

smaller releases continuing up to week 13 (Figs. $1 \mathrm{~A}$ and 2A). After week 2, Granubor released at a linear rate until approximately weeks 11 or 12 (Figs. IA and 2A). It continued to release at lower rates until approximately week 16, when it was nearly exhausted. Ultimately, Granubor released $100 \%$ of its B (Fig. 2A).
$40 \%$ of the $\mathrm{B}$ in this product was released during that period. On the other hand, $\mathrm{B} 32 \mathrm{G}$ released at a more rapid rate during the first 15 weeks and then linearly through approximately week 65 (Figs. $1 \mathrm{~B}$ and 2B). In contrast with B38 G, B32 G ultimately released $\approx 84 \%$ of its $B$ during the 104-week experiment.

Of the three B-containing minerals tested, colemanite released linearly from week 6 through 87 and ultimately released $\approx 97 \%$ of its $B$ during the 104-week experiment (Figs. 1B and 2B). Probertite released at a slightly faster rate than colemanite during the first 36 weeks, but more slowly thereafter (Fig. 1B). After 104 weeks, probertite had released $\approx 90 \%$ of its B (Fig. 2B). After the first 3 to 6 weeks of relatively rapid release, ulexite released at a rather uniform rate until approximately week 45 (Fig. 1B). After that time, its release rate dropped off rapidly to virtually nothing after $\approx 60$ weeks (Figs. $1 \mathrm{~B}$ and $2 \mathrm{~B}$ ). Over the course of 104 weeks, $\approx 84 \%$ of the $\mathrm{B}$ in ulexite was recovered in our leachates (Fig. 2B).

\section{Discussion}

As expected, our results demonstrated that soluble B sources such as Solubor can be quickly leached through sand and would have to be applied frequently at low rates to provide similar availability to controlled-release sources. In high rainfall areas such as south Florida, palms growing in field nurseries or landscapes are often fertilized every 3 months with complete fertilizer products containing controlled-release nitrogen, potassium, and magnesium (Broschat, 2005). Controlled-release B sources such as Granubor have release curves that would be suitable for blending with other elemental sources that have 3 -month longeveties. In areas where more soluble fertilizers are used, fasterrelease $B$ sources such as boric oxide or Dehybor might be preferable for blending.

If $B$ fertilizers are to be applied alone rather than blended with other components, then the longer-term products such as B32 G, colemantite, probertite, or ulexite may be useful for preventing $\mathrm{B}$ deficiencies. Inclusion of these very slow-release B sources into blended complete fertilizers that are applied at 3-month 
intervals or other relatively short intervals could result in an accumulation of B in the soil in the long term, potentially to toxic levels. Whereas B toxicity from soluble sources such as Solubor can be alleviated by heavy leaching, such leaching would be relatively ineffective in reducing B toxicities caused by excessive application of long-term controlled-release B fertilizers (Nable et al., 1997). The release curves presented here should be useful in determining safe reapplication intervals. However, additional research is needed with these products to determine optimum application rates for various crops and environments.

One additional benefit of some of these controlled-release B fertilizers is their granular particle size. When powdered B sources are blended into granular complete fertilizers, the powder quickly settles out, resulting in low B concentrations in fertilizer at the top and excessive amounts at the bottom of the container. Of the products tested, Granubor, B32 G, and B38 G have granules similar in size to other commonly used nitrogen, phosphorus, and potassium sources and would be suitable for blending with them. Boric oxide, Dehybor, colemanite, and probertite have fine granules or crystals and are less well suited for blending. Solubor and the ulexite that we tested are fine powders and are unsuitable for blending. The more rapid release of ulexite than of probertite and colemanite is likely the result of the finer particle size of the ulexite (Table 1) (Mortvedt, 1994; Wear and Wilson, 1954).

In summary, the release rates of most of the materials tested were fairly linear until $\approx 80 \%$ of their $\mathrm{B}$ content had been released. They represent a wide range of release rates, with Solubor releasing the fastest followed by boric oxide, Dehybor, Granubor, probertite and ulexite, B32 G, Colemanite, and B38 G, the latter releasing less than $40 \%$ of its B during the 2-year study. Particle sizes for Granubor, B32 G, and B38 G are suitable for blending with other granular fertilizers; however, the fine particle size of the other products may limit their use to separate applications.

\section{Literature cited}

Biggar, J.W. and M. Fireman. 1960. Boron adsorption and release by soils. Soil Sci. Soc. Amer. Proc. 24:115-120.

Broschat, T.K. 2005. Fertilization of field-grown and landscape palms in Florida. Univ. Florida Environ. Hort. Dept. Circ. ENHI009.

Broschat, T.K. 2007. Boron deficiency symptoms in palms. Palms 51: 115-126.

Corrado, F., P. Quencez, and B. Taillez. 1992. La déficience en bore chez le palmiera à huile. Symptômes et corrections. Oléagineux 47:719-725.

Hewitt, E.J. 1952. Sand and water culture methods used in the study of plant nutrition. Tech. Commun. No. 22. Commonwealth Agricultural Bureau, East Malling, UK.

Keren, R. 1996. Boron, p. 603-626. In: Bartels, J.M. (ed.). Methods of soil analysis. Part 3. Chemical methods. Soil Sci. Soc. Amer., Madison, WI.

Keren, R. and R.G. Gast. 1981. Effects of wetting and drying and of exchangeable cations on boron adsorption and release by montmorillonite. Soil Sci. Soc. Amer. J. 45:478-482.
Manciot, R., M. Ollagnier, and R. Ochs. 1980. Mineral nutrition and fertilization of the coconut around the world. Oléagineux 35:13-27.

Martens, D.C. and D.T. Westermann. 1991. Fertilizer applications for correcting micronutrient deficiencies, p. 549592. In: Mortvedt, J.J., F.R. Cox, L.M. Shuman, and R.M. Welch (eds.). Micronutrients in agriculture. 2nd ed. Soil Sci. Soc. Amer., Madison, WI.

Moraghan, J.T. and H.J. Mascagni, Jr. 1991. Environmental and soil factors affecting micronutrient deficiencies and toxicities, p. 371-425. In: Mortvedt, J.J. F.R. Cox, L.M. Shuman, and R.M. Welch (eds.). Micronutrients in agriculture, 2 nd ed. Soil Sci. Soc. Amer., Madison, WI.

Mortvedt, J.J. 1994. Needs for controlled-availability micronutrient fertilizers. Fert. Res. 38:213-221.

Nable, R.O., G.S. Bañuelos, and J.G. Paull. 1997. Boron toxicity. Plant Soil 193:181-198.

Page, N.R. and H.P. Cooper. 1955. Less soluble boron compounds for correcting boron nutritional deficiencies. J. Agr. Food Chem. 3:222-225.

Peryea, F.J., F.T. Bingham, and J.D. Rhodes. 1985. Mechanisms for boron regeneration. Soil Sci. Soc. Amer. J. 49: 840-843.

Reisenauer, H.M., L.M. Walsh, and R.G. Hoeft. 1973. Testing soils for sulphur, boron, molybdenum, and chlorine, p. 173-200. In: Walsh, L.M. and J.D. Beaton (eds.). Soil testing and plant analysis. Soil Sci. Soc. Amer, Madison, WI.

Sharrocks, V.M. 1997. The occurrence and correction of boron deficiency. Plant Soil 193:121-148.

Wear, J.I. and L.M. Wilson. 1954. Boron materials of low solubility and their uses for plant growth. Soil Sci. Soc. Amer. Proc. 18:425-428. 